\title{
CYP3A4 and CYP11A1 variants are risk factors for ischemic stroke: a case control study
}

\author{
Ning Gao, Hong Tang, Ling Gao, Guolong Tu, Han Luo and Ying Xia*
}

\begin{abstract}
Background: This study aimed to investigate the roles of CYP3A4 and CYP11A1 variants in ischemic stroke (IS) susceptibility among the Han Chinese population.

Methods: Four hundred seventy-seven patients with IS and 493 healthy controls were enrolled. Seven singlenucleotide polymorphisms (SNPs) of CYP3A4 and CYP11A1 were genotyped by Agena MassARRAY. Odds ratio (OR) and $95 \%$ confidence intervals $(\mathrm{Cl})$ were calculated by logistic regression adjusted for age and gender.

Results: We found that CYP3A4 rs3735451 (OR $=0.81, p=0.039)$ and rs4646440 (OR=0.72, $p=0.021)$ polymorphisms decreased the risk of IS. CYP3A4 rs4646440 (OR=0.74, $p=0.038)$ and CYP11A1 rs12912592 (OR=1.58, $p=0.034)$ polymorphisms were correlated with IS risk in males. CYP3A4 rs3735451 (OR=0.63, $p=0.031)$ and rs4646440 (OR $=0.57$, $p=0.012)$ possibly weaken the IS susceptibility at age $>61$ years. Besides, CYP3A4 rs4646437 (OR $=0.59, p=0.029)$, CYP11A1 rs12912592 (OR $=1.84, p=0.017)$ and $\mathrm{rs} 28681535(\mathrm{OR}=0.66, p=0.038)$ were associated with IS risk at age $\leq$ 61 years. CYP11A1 rs28681535 Tा genotype was higher high-density lipoprotein cholesterol level than the GT and GG genotype $(p=0.027)$.
\end{abstract}

Conclusions: Our findings indicated that rs3735451, rs4646440, rs4646437 in CYP3A4 and rs28681535 in CYP11A1 might be protective factors for IS, while CYP11A1 rs 12912592 polymorphism be a risk factor for IS in Chinese Han population.

Keywords: Ischemic stroke, CYP3A4, CYP11A1, Polymorphism, Susceptibility

\section{Background}

Stroke, a common multifactor neurological disease, is a common cause of death and severe disability in adults worldwide. The incidence of stroke is estimated to be more than 2 million people and more than 1 million people die from stroke-related causes every year in the Chinese population [1]. There are huge economic and social burdens because of stroke in China, which remains particularly high in the northern and central regions [2]. Ischemic stroke (IS) is the most common type of stroke accounting for $80-85 \%$ of all stroke cases [3]. According to epidemiologic studies, the incidence of IS in China is significantly higher than in developed countries [4]. The pathophysiological causes of IS are unclear,

\footnotetext{
*Correspondence: xiaying008@163.com

Department of Neurosurgery, Affiliated Haikou Hospital of Xiangya Medical College of Central South University, Haikou People's Hospital, \#43, People's Avenue, Haidian Island, Haikou 570208, Hainan, China
}

but the widely accepted concept is that IS is caused by the interaction between genetic and environmental factors [5]. To date, many studies have identified that gene polymorphisms modulate the pathophysiological processes of IS and confer a small to moderate risk [6-8].

Cytochrome P450s (CYPs) is a group of complexes and structurally related enzymes with diverse metabolic and biosynthetic activities. CYP epoxygenases is metabolizing arachidonic acid (AA) to biologically active epoxyeicosatrienoic acids (EETs), which exert vascular relaxation effects and have diverse protective roles in the cardiovascular system [9]. Previous studies have shown that plasma CYP metabolite levels, including EETs are associated with IS [10, 11]. CYP3A4 gene, located on chromosome $7 \mathrm{q} 21.1$, is a member of the CYP3A gene family, which participates in metabolizing arachidonic acid (AA) into epoxyeicosatrienoic acids (EETs) [12]. CYP11A1 gene is located on 
chromosome 15q23-q24, and is involved in the metabolism of cholesterol and vitamin $\mathrm{D}$, which associated with cardiovascular diseases [13, 14]. Consequently, studies concerning the possible association of CYP3A4 and CYP11A1 gene with IS may be particularly interesting for their potential biological significance.

However, few reports concerning the role of CYP3A4 and CYP11A1 polymorphisms on IS risk have been published yet. Therefore, we carried out a case-control study to explore whether polymorphisms in CYP3A4 and CYP11A1 contribute to the risk of IS in a Chinese Han population.

\section{Methods}

\section{Study participants}

A cohort of 477 IS patients and 495 control subjects were enrolled from Haikou People's Hospital and the Affliated Hospital of Yan'an University in this study. All recruited subjects were unrelated ethnic Han Chinese. All the patients were identified as having newly diagnosed IS by at least two independent neurologists, according to the clinical signs and symptoms. All patients underwent brain computed tomography (CT) scans and/ or magnetic resonance imaging (MRI) as well as standardized clinical hematology, biochemistry and immunology examinations. Patients with a history of hematologic, coronary artery diseases, autoimmune diseases, systemic inflammatory diseases, blood diseases, or malignant tumors were excluded. The healthy individuals without the history of stroke, normal neurological examination results, and free from cardiovascular and cerebrovascular diseases, and immunological diseases, who received a physical examination in the same hospital, were recruited as controls. Demographic characteristics, clinical information and medications were collected with standardized questionnaires. The following clinical data were collected: age, gender, total protein, serum uric acid, blood glucose, total bilirubin, total cholesterol, triglyceride, low-density lipoprotein and high-density lipoprotein. This study protocol was approved by the Ethics Committee of Haikou People's Hospital and was conducted according to the guidelines on the Declaration of Helsinki. Informed consent was obtained from all participants.

\section{Sample collection and SNP genotyping}

Blood samples were obtained from the peripheral veins and were stored in EDTA-coated tubes at -80C until further analysis. Genomic DNA was isolated from peripheral blood samples using the GoldMag DNA Purification Kit (GoldMag Co. Ltd., Xi'an City, China) according to the manufacturer's instructions. The DNA concentration and purity was determined using NanoDrop 2000 (Thermo Scientifc, Waltham, MA, USA). Four CYP3A4 SNPs (rs3735451, rs4646440, rs35564277 and rs4646437) and three CYP11A1 SNPs (rs1484215, rs12912592 and rs28681535) were selected based on the NCBI SNP database and minor allele frequencies (MAFs) $>5 \%$ in the 1000 Genomes Project data (http://www.internationalgenome.org/). In order to uncover the functional effects of CYP3A4 and CYP11A1 polymorphisms, online software for HaploReg v4.1 (https://pubs.broadinstitute.org/mammals/haploreg/haploreg.php) was used.

The MassARRAY platform is based on MALDI-TOF (matrix-assisted laser desorption/ionization-time of flight) mass spectrometry in a high-throughput and cost-effective manner $[15,16]$. The advantage of MassARRAY platform is 1) multiplex PCR assays for up to 40 SNPs simultaneously; 2) relatively forgiving in terms of required DNA quality and quantity; 3) The primers design and the data management were implemented using Agena Design 3.0 Software and Agena Typer 4.0 software, respectively. Therefore, in our study, SNPs genotyping were performed using Agena MassARRAY system (Agena, San Diego, CA, U.S.A.) as previously described, and conducted by laboratory technicians blinded to the case-control status. The primers for PCR amplification and single base extension were present in Additional file 1: Table S1. Approximately $10 \%$ of samples were randomly selected to repeat genotyping for quality control, and a 100\% concordant was achieved.

\section{Data analysis}

Statistical analyses were performed using SPSS version 18.0 (SPSS Inc., Chicago, IL, USA) and PLINK software. Demographic data of patients and controls were compared using student's t-test and chi-square test. HardyWeinberg equilibrium (HWE) was examined via a goodness-of-fit $\chi^{2}$ test to compare the observed genotype frequencies and the expected frequencies among the control subjects. The genotype and allele frequencies of the controls and IS patients were compared using the $x^{2}$ test or Fisher's exact test. The correlation between CYP3A4 and CYP11A1 polymorphisms and IS susceptibility was estimated by odds ratios (ORs) and 95\% confidence intervals (CIs) using logistic regression analysis with adjustment for age and sex by PLINK software. Multiple inheritance models (genotype, dominant, recessive and log-additive) were estimated. Further, we calculated stratification factors using age ( $\leq 61$ and $>61$ years) and gender (male and female) to adjust for possible cofounders. Pairwise linkage disequilibrium (LD) between the selected SNPs was measured by the LD coefficient D' using the Haploview software (version 4.2), and haplotype analyses were performed by logistic regression analysis using the PLINK software. Finally, the association between the genotypes of CYP3A4 and CYP11A1 polymorphisms and clinical parameters was tested by 
covariance analysis (ANCOVA). A two-tailed $p$-value < 0.05 was considered as significant.

\section{Results}

In total, 477 IS patients (316 males and 161 females) and 493 control subjects (325 males and 168 females) were recruited. There were no significant differences between patients and controls in terms of gender $(p=0.898)$. The mean age was $64.13 \pm 10.82$ years for the patients with IS and $60.05 \pm 6.56$ years for the control subjects. Significant differences were also found in age distribution $(p<$ $0.001)$, suggesting that age may have an effect on the etiology of IS. The total protein, serum uric acid, blood glucose, bilirubin, triglyceride, hemoglobin, cholesterol and low-density lipoprotein levels in the IS patients were significantly different from those noted in the healthy control subjects. The clinical characteristics of the patients were described in Table 1.

Seven SNPs in CYP3A4 and CYP11A1 were successfully genotyped, and the average variant call rate was 99.6\%. Detailed information and potential function of candidate SNPs were listed in Table 2. These intronic SNPs were associated with the regulation of promoter and/or enhancer histones, changed motifs, and selected eQTL hits, suggesting they might exert biology functions in silico. MAF of all SNPs was higher than $5 \%$ of the study population. All SNPs were in HWE among the controls $(p>0.05)$.

The allele and genotype frequency distributions of the SNPs and their association with IS susceptibility were shown in Table 3 and Additional file 1: Table S2. CYP3A4 SNPs rs3735451 and rs4646440 were associated with reduced susceptibility of IS (Table 3 ). We found that individuals carrying rs3735451-C allele had a decreased risk of IS in allele model $(\mathrm{OR}=0.81,95 \% \mathrm{CI}$ : $0.66-0.98, p=0.039)$, genotype model $(\mathrm{OR}=0.74,95 \%$
CI: $0.57-0.97, p=0.029)$, dominant model $(\mathrm{OR}=0.73$, 95\% CI: $0.56-0.95, p=0.018)$ and additive model (rs3735451 OR $=0.78,95 \%$ CI: 0.63-0.96, $p=0.019)$, respectively. With rs4646440 GG genotype as reference, the presence of the GA genotype was associated with a significantly decreased risk of IS after adjustment for age and gender (GA vs. GG, OR $=0.72,95 \% \mathrm{CI}: 0.55-0.95$, $p=0.021$; GA-AA vs. GG, OR $=0.72,95 \%$ CI: $0.55-0.94$, $p=0.017$, Table 3 ). Furthermore, rs4646440 polymorphism also might reduce the susceptibility to IS under additive model (OR $=0.77$, 95\% CI: $0.61-0.97, p=0.024$ ). Nevertheless, other polymorphisms in CYP3A4 and CYP11A1 did not relate to IS susceptibility (Additional file 1: Table S2).

We further analyzed whether the genotypic effects on IS risk were dependent on gender (Table 4). We found that CYP3A4 rs4646440 was associated with a decreased risk under the additive model $(\mathrm{OR}=0.74$, 95\% CI: $0.56-0.98, p=0.038)$, and showed a marginal $p$ value in allele model $(\mathrm{OR}=0.76,95 \% \mathrm{CI}: 0.58-1.00$, $p=0.050$ ) among males, which indicated insufficient evidence for claiming an association. CYP11A1 rs12912592 polymorphism also showed significant risk-increasing effects in the heterozygote model $(\mathrm{OR}=1.58,95 \% \mathrm{CI}: 1.04-2.42, p=0.034)$, and dominant model (OR $=1.56,95 \%$ CI: $1.02-2.37, p=0.039)$.

In the stratification of age, CYP3A4 SNPs rs3735451 and rs4646440 were associated with the susceptibility to IS at age $>61$ years (Table 5). For rs3735451, the C allele carriers had a decreased risk of IS $(\mathrm{OR}=0.63$, 95\% CI: $0.41-0.96, p=0.031$ for CT vs. TT genotypes; $\mathrm{OR}=0.65,95 \%$ CI: $0.43-0.97, p=0.036$ for CT-CC vs. TT genotypes) after adjusting for age and gender. For rs4646440, we found that the A allele was significantly associated with a reduced risk of IS (GA vs.GG, $\mathrm{OR}=0.57,95 \% \mathrm{CI}: 0.37-0.88, p=0.012$; and

Table 1 Characteristics of patients with ischemic stroke and controls

\begin{tabular}{llll}
\hline Characteristics & Cases $(n=477)$ & Controls $(n=493)$ & $p$ \\
\hline Age, year (mean \pm SD) & $64.13 \pm 10.82$ & $60.05 \pm 6.56$ & $<0.001$ \\
Gender $(\mathrm{M} / \mathrm{F})$ & $316 / 161$ & $325 / 168$ & 0.898 \\
TP $(\mathrm{g} / \mathrm{L}$, mean $\pm \mathrm{SD})$ & $65.57 \pm 5.80$ & $70.88 \pm 5.61$ & $<0.001$ \\
Serum uric acid $(\mu \mathrm{mol} / \mathrm{L}$, mean $\pm \mathrm{SD})$ & $284.53 \pm 94.37$ & $330 \pm 80.27$ & $<0.001$ \\
Blood glucose $(\mathrm{mmol} / \mathrm{L}$, mean $\pm \mathrm{SD})$ & $6.33 \pm 2.24$ & $5.83 \pm 1.44$ & 0.001 \\
TB $(\mu$ mol/L, mean $\pm S D)$ & $13.63 \pm 6.51$ & $17.00 \pm 5.94$ & $<0.001$ \\
TG $($ mmol/L, mean $\pm S D)$ & $1.59 \pm 1.05$ & $4.50 \pm 0.92$ & $<0.001$ \\
Hemoglobin (g/L, mean $\pm S D)$ & $136.87 \pm 22.77$ & $147.76 \pm 14.31$ & $<0.001$ \\
TC (mmol/L, mean $\pm S D)$ & $3.89 \pm 1.03$ & $1.79 \pm 1.16$ & $<0.001$ \\
HDL-C (mmol/L, mean $\pm S D)$ & $1.09 \pm 0.26$ & $1.09 \pm 0.23$ & 0.871 \\
LDL-C (mmol/L, mean $\pm S D)$ & $1.81 \pm 0.58$ & $2.56 \pm 0.71$ & $<0.001$ \\
\hline
\end{tabular}

$S D$ standard deviation, $T P$ total protein, $T B$ total bilirubin, $T G$ triglyceride, $T C$ total cholesterol, $H D L-C$ high-density lipoprotein cholesterol, $L D L-C$ lowdensity lipoprotein cholesterol 
Table 2 The information about the candidate SNPs in CYP3A4 and CYP11A1

\begin{tabular}{|c|c|c|c|c|c|c|}
\hline \multirow[t]{2}{*}{ Gene } & \multirow[t]{2}{*}{ SNP ID } & \multirow{2}{*}{$\begin{array}{l}\text { Chr: } \\
\text { Position }\end{array}$} & \multirow{2}{*}{$\begin{array}{l}\text { Alleles } \\
\text { (minor/major) }\end{array}$} & \multicolumn{2}{|c|}{ Frequency (MAF) } & \multirow[t]{2}{*}{ HaploReg } \\
\hline & & & & Case & Control & \\
\hline CYP3A4 & rs3735451 & 7:99758352 & $\mathrm{C} / \mathrm{T}$ & 0.26 & 0.30 & Motifs Changed, Selected eQTL hits \\
\hline CYP3A4 & rs4646440 & 7:99763247 & $A / G$ & 0.19 & 0.23 & $\begin{array}{l}\text { Promoter histone marks, } \\
\text { Enhancer histone marks, DNAse, } \\
\text { Proteins bound, Motifs changed, } \\
\text { Selected eQTL hits }\end{array}$ \\
\hline CYP3A4 & rs35564277 & 7:99764813 & $\mathrm{C} / \mathrm{T}$ & 0.06 & 0.07 & Motifs Changed \\
\hline CYP3A4 & rs4646437 & 7:99767460 & $A / G$ & 0.11 & 0.13 & $\begin{array}{l}\text { Promoter histone marks, } \\
\text { Enhancer histone marks, } \\
\text { Motifs changed, } \\
\text { Selected eQTL hits }\end{array}$ \\
\hline CYP11A1 & rs1484215 & $15: 74347768$ & $\mathrm{~T} / \mathrm{C}$ & 0.18 & 0.18 & $\begin{array}{l}\text { Enhancer histone marks, } \\
\text { Motifs changed, } \\
\text { Selected eQTL hits }\end{array}$ \\
\hline CYP11A1 & rs12912592 & 15:74363369 & $T / G$ & 0.10 & 0.08 & $\begin{array}{l}\text { Enhancer histone marks, } \\
\text { Motifs changed, } \\
\text { Selected eQTL hits }\end{array}$ \\
\hline CYP11A1 & rs28681535 & $15: 74367268$ & $T / G$ & 0.43 & 0.45 & $\begin{array}{l}\text { Promoter histone marks, } \\
\text { Enhancer histone marks, } \\
\text { DNAse, Motifs changed }\end{array}$ \\
\hline
\end{tabular}

MAF minor allele frequency, eQTL expression quantitative trait loci

Table 3 Relationships between CYP3A4 and CYP11A1 polymorphism and ischemic stroke risk

\begin{tabular}{|c|c|c|c|c|c|c|}
\hline \multirow{2}{*}{$\begin{array}{l}\text { Gene SNP } \\
\text { ID }\end{array}$} & \multirow[t]{2}{*}{ Model } & \multirow[t]{2}{*}{ Genotype } & \multirow[t]{2}{*}{ Case } & \multirow[t]{2}{*}{ Control } & \multicolumn{2}{|c|}{ Adjusted by age and gender } \\
\hline & & & & & OR $(95 \% \mathrm{Cl})$ & $p$ \\
\hline \multirow{10}{*}{$\begin{array}{l}\text { CYP3A4 } \\
\text { rs3735451 }\end{array}$} & \multirow[t]{2}{*}{ Allele } & $\mathrm{T}$ & 705 & 686 & 1.00 & 0.039 \\
\hline & & C & 249 & 300 & $0.81(0.66-0.98)$ & \\
\hline & \multirow[t]{3}{*}{ Genotype } & $\pi$ & 256 & 228 & 1.00 & \\
\hline & & $\mathrm{CT}$ & 193 & 230 & $0.74(0.57-0.97)$ & 0.029 \\
\hline & & CC & 28 & 35 & $0.66(0.38-1.14)$ & 0.135 \\
\hline & \multirow[t]{2}{*}{ Dominant } & $\pi$ & 256 & 228 & 1.00 & 0.018 \\
\hline & & CT-CC & 221 & 265 & $0.73(0.56-0.95)$ & \\
\hline & \multirow[t]{2}{*}{ Recessive } & $\mathrm{TT}-\mathrm{CT}$ & 449 & 458 & 1.00 & 0.308 \\
\hline & & CC & 28 & 35 & $0.76(0.45-1.29)$ & \\
\hline & Log-additive & - & - & - & $0.78(0.63-0.96)$ & 0.019 \\
\hline \multirow{10}{*}{$\begin{array}{l}\text { CYP3A4 } \\
\text { rs4646440 }\end{array}$} & \multirow[t]{2}{*}{ Allele } & G & 768 & 754 & 1.00 & 0.046 \\
\hline & & A & 186 & 228 & $0.80(0.64-1.00)$ & \\
\hline & \multirow[t]{3}{*}{ Genotype } & GG & 307 & 282 & 1.00 & \\
\hline & & $\mathrm{GA}$ & 154 & 190 & $0.72(0.55-0.95)$ & 0.021 \\
\hline & & $\mathrm{AA}$ & 16 & 19 & $0.72(0.36-1.45)$ & 0.362 \\
\hline & \multirow[t]{2}{*}{ Dominant } & GG & 307 & 282 & 1.00 & 0.017 \\
\hline & & GA-AA & 170 & 209 & $0.72(0.55-0.94)$ & \\
\hline & \multirow[t]{2}{*}{ Recessive } & GG-GA & 461 & 472 & 1.00 & 0.560 \\
\hline & & $\mathrm{AA}$ & 16 & 19 & $0.81(0.41-1.62)$ & \\
\hline & Log-additive & - & - & - & $0.77(0.61-0.97)$ & 0.024 \\
\hline
\end{tabular}

SNP single nucleotide polymorphism, OR odds ratio, 95\% Cl 95\% confidence interval

$p$ values were calculated by logistic regression analysis with adjustments for age and gender

$p<0.05$ means the data is statistically significant

Bold indicates that the values have statistical significance 
Table 4 Relationships between CYP3A54 and CYP11A1 polymorphism and ischemic stroke risk according to the stratification by gender

\begin{tabular}{|c|c|c|c|c|c|c|c|c|c|c|}
\hline \multirow[t]{2}{*}{ SNP ID } & \multirow[t]{2}{*}{ Model } & \multirow[t]{2}{*}{ Genotype } & \multicolumn{4}{|l|}{ Male } & \multicolumn{4}{|c|}{ Female } \\
\hline & & & Case & Control & OR $(95 \% \mathrm{Cl})$ & $p$ & Case & Control & OR $(95 \% \mathrm{Cl})$ & $p$ \\
\hline \multirow{10}{*}{$\begin{array}{l}\text { CYP3A4 } \\
\text { rs4646440 }\end{array}$} & \multirow[t]{2}{*}{ Allele } & G & 509 & 492 & 1.00 & \multirow[t]{2}{*}{0.050} & 259 & 262 & 1.00 & \multirow[t]{2}{*}{0.563} \\
\hline & & A & 123 & 156 & $0.76(0.58-1.00)$ & & 63 & 72 & $0.89(0.61-1.29)$ & \\
\hline & \multirow[t]{3}{*}{ Genotype } & GG & 202 & 183 & 1.00 & 0.117 & 105 & 99 & 1.00 & 0.226 \\
\hline & & GA & 105 & 126 & $0.74(0.53-1.05)$ & 0.089 & 49 & 64 & $0.69(0.43-1.11)$ & 0.123 \\
\hline & & $\mathrm{AA}$ & 9 & 15 & $0.53(0.22-1.27)$ & 0.156 & 7 & 4 & $1.44(0.40-5.15)$ & 0.576 \\
\hline & \multirow[t]{2}{*}{ Dominant } & GG & 202 & 183 & 1.00 & \multirow[t]{2}{*}{0.052} & 105 & 99 & 1.00 & \multirow[t]{2}{*}{0.188} \\
\hline & & GA-AA & 114 & 141 & $0.72(0.52-1.00)$ & & 56 & 68 & $0.74(0.47-1.16)$ & \\
\hline & \multirow[t]{2}{*}{ Recessive } & GG-GA & 307 & 309 & 1.00 & \multirow[t]{2}{*}{0.237} & 154 & 163 & 1.00 & \multirow[t]{2}{*}{0.438} \\
\hline & & AA & 9 & 15 & $0.60(0.25-1.41)$ & & 7 & 4 & $1.65(0.47-5.81)$ & \\
\hline & Log-additive & - & - & - & $0.74(0.56-0.98)$ & 0.038 & - & - & $0.83(0.56-1.24)$ & 0.371 \\
\hline \multirow{10}{*}{$\begin{array}{l}\text { CYP11A1 } \\
\text { rs12912592 }\end{array}$} & \multirow[t]{2}{*}{ Allele } & G & 565 & 602 & 1.00 & \multirow[t]{2}{*}{0.081} & 297 & 301 & 1.00 & \multirow[t]{2}{*}{0.672} \\
\hline & & T & 67 & 50 & $1.43(0.97-2.10)$ & & 25 & 29 & $0.87(0.50-1.53)$ & \\
\hline & \multirow[t]{3}{*}{ Genotype } & GG & 250 & 277 & 1.00 & & 138 & 136 & 1.00 & \\
\hline & & GT & 65 & 48 & $1.58(1.04-2.42)$ & 0.034 & 21 & 29 & $0.64(0.34-1.19)$ & 0.161 \\
\hline & & $\Pi$ & 1 & 1 & $0.63(0.04-10.19)$ & 0.743 & 2 & 0 & / & / \\
\hline & \multirow[t]{2}{*}{ Dominant } & GG & 250 & 277 & 1.00 & \multirow[t]{2}{*}{0.039} & 138 & 136 & 1.00 & \multirow[t]{2}{*}{0.224} \\
\hline & & GT-TT & 66 & 49 & $1.56(1.02-2.37)$ & & 23 & 29 & $0.70(0.38-1.28)$ & \\
\hline & \multirow[t]{2}{*}{ Recessive } & GG-GT & 315 & 325 & 1.00 & \multirow[t]{2}{*}{0.704} & 159 & 165 & 1.00 & \multirow[t]{2}{*}{ / } \\
\hline & & $\Pi$ & 1 & 1 & $0.58(0.04-9.45)$ & & 2 & 0 & / & \\
\hline & Log-additive & - & - & - & $1.51(1.00-2.28)$ & 0.051 & - & - & $0.78(0.44-1.38)$ & 0.393 \\
\hline
\end{tabular}

SNP single nucleotide polymorphism, OR odds ratio, 95\% Cl 95\% confidence interval

$p$ values were calculated by logistic regression analysis with adjustments for age and gender

$p<0.05$ indicates statistical significance

Bold indicates that the values have statistical significance

GA-AA vs.GG OR $=0.60,95 \%$ CI: $0.40-0.91, p=0.017$ ). Among the population under the age of 61 , we found that CYP3A4 rs4646437, CYP11A1 rs12912592 and rs28681535 were associated with IS risk. CYP3A4 rs4646437 and CYP11A1 rs28681535 polymorphisms were significantly associated with decreased risk for IS (rs4646437, OR $=0.59,95 \%$ CI: $0.37-0.95, p=0.029$; and rs28681535, OR $=0.66,95 \% \mathrm{CI}: 0.45-0.98, p=0.038$ ). Additionally, the carriers of the $\mathrm{T}$ allele at CYP11A1 rs12912592 appeared to have a higher risk of IS (T vs G, $\mathrm{OR}=1.64,95 \%$ CI: $1.04-2.61, p=0.043$; GT vs GG, OR = 1.84, 95\% CI: $1.11-3.05, p=0.017$ and GT-TT vs GG, $\mathrm{OR}=1.89,95 \%$ CI: $1.15-3.12, p=0.013)$.

We next performed haplotype analyses, and the results showed that CYP3A4 rs4646440 was in strong linkage disequilibrium (LD) with rs35564277. Additionally, three CYP11A1 SNPs (rs1484215, rs12912592, and rs28681535) were in strong LD, as shown in Fig. 1. However, no association of the haplotypes in CYP3A4 and CYP11A1 was found (Table 6).

Furthermore, we also assessed the association of the selected SNPs and clinical variables in patients (Table 7). Significant association was observed between the genotypes of the CYP3A4 SNPs rs3735451 and rs4646440 and the levels of total protein $(p=0.021$ and $p=0.043$, respectively). A significant association of CYP11A1 rs12912592 polymorphism with total bilirubin was identified $(p=0.025)$. Besides, the TT genotype of CYP11A1 rs28681535 was higher high-density lipoprotein cholesterol level than GT genotype and GG genotype $(p=0.027)$. However, there was no difference in the remaining lipid parameters among the genotypes of the selected SNPs $(p>0.05$ for all).

\section{Discussion}

The aim of this investigation was to discover whether there was an association between the CYP3A4 and CYP11A1 polymorphisms and IS risk in Chinese population. In this study, we found that $\mathrm{C}$ allele and $\mathrm{CT}$ genotype of rs3735451 and GA genotype of rs4646440 in CYP3A4 were significantly associated with a reduced risk of IS in the overall. We further demonstrated that CYP3A4 rs4646440 was associated with a decreased risk of IS, whereas CYP11A1 rs12912592 was associated with a higher risk of IS in males. In addition, our study found that CYP3A4 rs3735451 and rs4646440 possibly 
Table 5 Relationships between CYP3A4 and CYP11A1 polymorphism and ischemic stroke risk according to the stratification by age

\begin{tabular}{|c|c|c|c|c|c|c|c|c|c|}
\hline \multirow[t]{2}{*}{ SNP ID } & \multirow{2}{*}{$\begin{array}{l}\text { Allele/ } \\
\text { Genotype }\end{array}$} & \multicolumn{4}{|l|}{$>61$} & \multicolumn{4}{|l|}{$\leq 61$} \\
\hline & & Case & Control & OR $(95 \% \mathrm{Cl})$ & $p$ & Case & Control & OR $(95 \% \mathrm{Cl})$ & $p$ \\
\hline \multirow{6}{*}{$\begin{array}{l}\text { CYP3A4 } \\
\text { rs3735451 }\end{array}$} & $T$ & 403 & 287 & 1.00 & 0.063 & 302 & 399 & 1.00 & 0.217 \\
\hline & C & 145 & 135 & $0.76(0.58-1.01)$ & & 104 & 165 & $0.83(0.62-1.11)$ & \\
\hline & $\pi$ & 148 & 92 & 1.00 & & 108 & 136 & 1.00 & \\
\hline & $C T$ & 107 & 103 & $0.63(0.41-0.96)$ & 0.031 & 86 & 127 & $0.85(0.58-1.24)$ & 0.388 \\
\hline & CC & 19 & 16 & $0.77(0.35-1.70)$ & 0.514 & 9 & 19 & $0.63(0.27-1.47)$ & 0.290 \\
\hline & $\mathrm{CT}-\mathrm{CC}$ & 126 & 119 & $0.65(0.43-0.97)$ & 0.036 & 95 & 146 & $0.82(0.57-1.18)$ & 0.288 \\
\hline \multirow{6}{*}{$\begin{array}{l}\text { CYP3A4 } \\
\text { rs4646440 }\end{array}$} & G & 439 & 314 & 1.00 & 0.051 & 329 & 440 & 1.00 & 0.334 \\
\hline & A & 109 & 106 & $0.74(0.54-1.00)$ & & 77 & 122 & $0.84(0.61-1.16)$ & \\
\hline & GG & 176 & 114 & 1.00 & & 131 & 168 & 1.00 & \\
\hline & GA & 87 & 86 & $0.57(0.37-0.88)$ & 0.012 & 67 & 104 & $0.82(0.56-1.21)$ & 0.321 \\
\hline & $A A$ & 11 & 10 & $0.86(0.33-2.25)$ & 0.764 & 5 & 9 & $0.79(0.26-2.44)$ & 0.684 \\
\hline & GA-AA & 98 & 96 & $0.60(0.40-0.91)$ & 0.017 & 72 & 113 & $0.82(0.56-1.20)$ & 0.302 \\
\hline \multirow{6}{*}{$\begin{array}{l}\text { CYP3A4 } \\
\text { rs4646437 }\end{array}$} & G & 486 & 368 & 1.00 & 0.487 & 360 & 485 & 1.00 & 0.284 \\
\hline & A & 62 & 54 & $0.87(0.59-1.28)$ & & 46 & 77 & $0.80(0.55-1.19)$ & \\
\hline & GG & 214 & 160 & 1.00 & & 163 & 207 & 1.00 & \\
\hline & GA & 58 & 48 & $0.81(0.49-1.32)$ & 0.396 & 34 & 71 & $0.59(0.37-0.95)$ & 0.029 \\
\hline & $A A$ & 2 & 3 & $0.48(0.06-3.65)$ & 0.478 & 6 & 3 & $2.41(0.57-10.25)$ & 0.233 \\
\hline & GA-AA & 60 & 51 & $0.79(0.49-1.28)$ & 0.335 & 40 & 74 & $0.67(0.43-1.04)$ & 0.073 \\
\hline \multirow{6}{*}{$\begin{array}{l}\text { CYP11A1 } \\
\text { rs12912592 }\end{array}$} & G & 498 & 376 & 1.00 & 0.659 & 364 & 527 & 1.00 & 0.043 \\
\hline & T & 50 & 42 & $0.90(0.58-1.38)$ & & 42 & 37 & $1.64(1.04-2.61)$ & \\
\hline & GG & 226 & 168 & 1.00 & & 162 & 245 & 1.00 & \\
\hline & GT & 46 & 40 & $0.93(0.55-1.58)$ & 0.798 & 40 & 37 & $1.84(1.11-3.05)$ & 0.017 \\
\hline & $\pi$ & 2 & 1 & $0.53(0.04-7.01)$ & 0.629 & 1 & 0 & / & / \\
\hline & GT-TT & 48 & 41 & $0.92(0.55-1.54)$ & 0.744 & 41 & 37 & $1.89(1.15-3.12)$ & 0.013 \\
\hline \multirow{6}{*}{$\begin{array}{l}\text { CYP11A1 } \\
\text { rs28681535 }\end{array}$} & G & 298 & 237 & 1.00 & 0.603 & 246 & 309 & 1.00 & 0.076 \\
\hline & $\mathrm{T}$ & 250 & 185 & $1.08(0.83-1.39)$ & & 160 & 255 & $0.79(0.61-1.02)$ & \\
\hline & GG & 75 & 67 & 1.00 & & 80 & 87 & 1.00 & \\
\hline & GT & 148 & 103 & $1.31(0.82-2.09)$ & 0.251 & 86 & 135 & $0.69(0.46-1.05)$ & 0.081 \\
\hline & $\pi$ & 51 & 41 & $1.10(0.61-1.99)$ & 0.743 & 37 & 60 & $0.60(0.36-1.02)$ & 0.061 \\
\hline & GT-TT & 199 & 144 & $1.25(0.81-1.95)$ & 0.318 & 123 & 195 & $0.66(0.45-0.98)$ & 0.038 \\
\hline
\end{tabular}

SNP, single nucleotide polymorphism; OR, odds ratio; $95 \% \mathrm{Cl}, 95 \%$ confidence interval $p$ values were calculated by logistic regression analysis with adjustments for age and gender $p<0.05$ indicates statistical significance

Bold indicates that the values have statistical significance

contributed to the susceptibility to IS at age $>61$ years, and rs4646437 in CYP3A4 and rs12912592 and rs28681535 in CYP11A1 were associated with the risk of IS at age $\leq 61$ years. Besides, the TT genotype of CYP11A1 rs28681535 was higher high-density lipoprotein cholesterol level than GT genotype and GG genotype $(p=0.027)$. To the best of our knowledge, this is the first study to demonstrate the association of these polymorphisms in CYP3A4 and CYP11A1 with IS risk in Chinese population.

CYP genes encode monooxygenases responsible for arachidonic acid metabolism, which is involved in cardiovascular diseases and stroke [17]. Numerous studies have suggested an association between genetic variants of CYP pathway genes and the risk of IS [18]. CYP3A4 gene encodes an enzyme, which involved in drug metabolism and synthesis of cholesterol, steroids and other lipids, and mediated the production of arachidonic acid metabolites $[19,20]$. CYP11A gene, a member of CYP genes, encodes a cholesterol side chain cleavage enzyme (cytochrome P450 cholesterol side-chain cleavage, P450scc) that plays a major role in the control of steroidogenesis, by mediating the conversion of cholesterol to pregnenolone [21]. Dyslipidemia such as low 


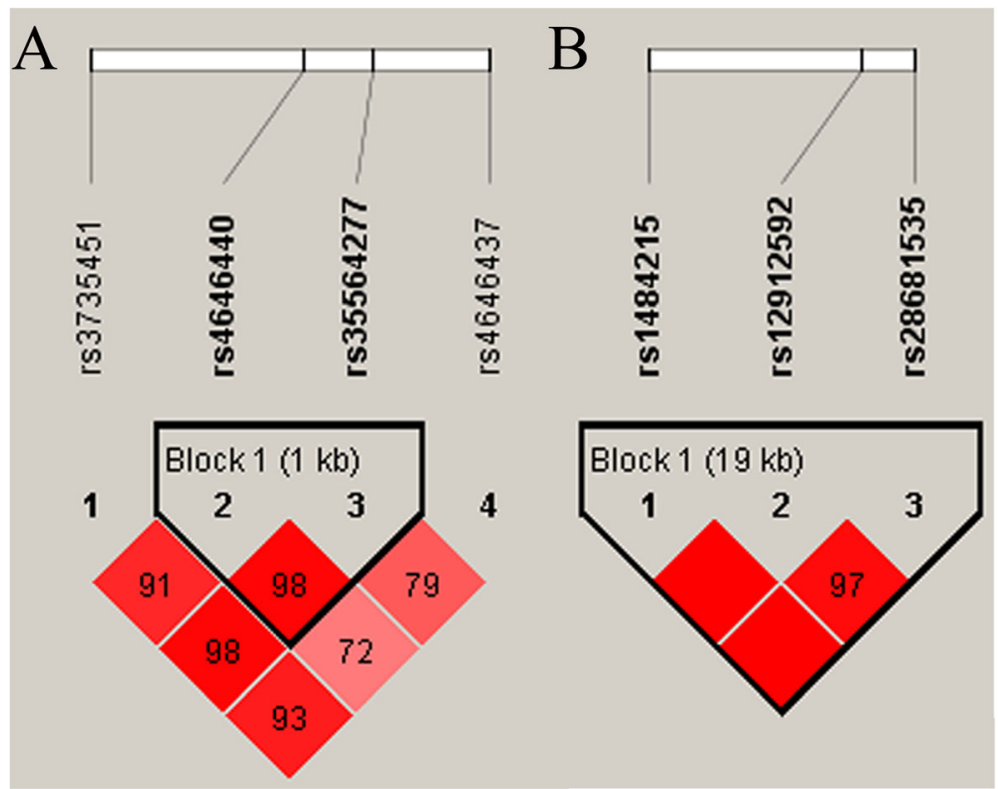

Fig. 1 Haplotype block map for SNPs in CYP3A4 (a) and CYP11A1 (b) gene. Numbers in squares are D' values in Fig. 1

concentration of high-density lipoprotein cholesterol (HDL-C), high levels of low-density lipoprotein cholesterol (LDL-C), total cholesterol (TC) was one of the most important risk factors of IS [22]. These lines of evidence have led us to formulate the hypothesis that CYP3A4 and CYP11A1 could be of pathogenic importance in IS.

Variations in the CYP3A4 or CYP11A1 genes may influence the gene expression, which might associate with the occurrence and progression of disease. In this study, we found that CYP3A4 (rs3735451, rs4646440 and rs4646437) and CYP11A1 (rs12912592 and rs28681535) polymorphisms were significantly associated with the risk of IS. These polymorphisms are located in the intron region. Chen $\mathrm{CH}$ er al. reported that rs4646440 was associated with higher CYP3A4 enzyme activities [23].
Reportedly, rs4646437 influences the protein expression and enzymatic activity of hepatic CYP3A4 [24]. The functional mechanism of other variants have not been reported in previous studies. The functional mechanism of these variants have not been reported in previous studies. Based on HaploReg database, we found these polymorphisms might be associated with the regulation of promoter/enhancer histone, DNAse, proteins binding and changed motifs and/or selected eQTL hits. Several studies provided increasing evidence to support that intronic SNPs confer susceptibilities by affecting gene expression [25-27]. Therefore, we hypothesized that CYP3A4 or CYP11A1 polymorphisms may affect the expression of their genes to contribute to the risk of IS. However, further study is necessary to confirm this hypothesis.

Table 6 Haplotype frequencies and their associations with ischemic stroke risk

\begin{tabular}{|c|c|c|c|c|c|c|c|c|}
\hline \multirow[t]{2}{*}{ Gene } & \multirow[t]{2}{*}{ SNP } & \multirow[t]{2}{*}{ Haplotype } & \multicolumn{2}{|c|}{ Frequency } & \multicolumn{2}{|l|}{ Crude analysis } & \multicolumn{2}{|c|}{ Adjusted by age and gender } \\
\hline & & & Case & Control & $\mathrm{OR}(95 \% \mathrm{Cl})$ & $p$ & OR $(95 \% \mathrm{Cl})$ & $p$ \\
\hline \multirow[t]{3}{*}{ CYP3A4 } & rs4646440|rs35564277 & GT & 0.805 & 0.768 & 1 & & 1 & \\
\hline & rs4646440|rs35564277 & AT & 0.138 & 0.159 & $0.82(0.63-1.06)$ & 0.130 & $0.78(0.60-1.02)$ & 0.070 \\
\hline & rs4646440|rs35564277 & $A C$ & 0.058 & 0.072 & $0.79(0.55-1.12)$ & 0.190 & $0.75(0.52-1.08)$ & 0.120 \\
\hline \multirow[t]{4}{*}{ CYP11A1 } & rs1484215|rs12912592|rs28681535 & CGT & 0.430 & 0.446 & 1 & & 1 & \\
\hline & rs1484215|rs12912592|rs28681535 & CGG & 0.294 & 0.290 & $1.07(0.87-1.31)$ & 0.550 & $1.06(0.85-1.31)$ & 0.600 \\
\hline & rs1484215|rs12912592|rs28681535 & TGG & 0.180 & 0.184 & $1.01(0.79-1.29)$ & 0.940 & $1.06(0.82-1.37)$ & 0.670 \\
\hline & rs1484215|rs12912592|rs28681535 & CTG & 0.096 & 0.080 & $1.29(0.92-1.81)$ & 0.130 & $1.24(0.87-1.75)$ & 0.230 \\
\hline
\end{tabular}

CYP3A4 block comprises the two closely linked SNPs rs4646440 and rs35564277. CYP11A14 block comprises the three closely linked SNPs rs1484215, rs12912592, and rs28681535

OR odds ratio, 95\% Cl 95\% confidence interval

$p$ values were calculated using logistic regression analysis with and without adjustment by gender and age 
Table 7 Comparisons of clinical characteristics among patients with different genotypes of selected SNPs

\begin{tabular}{|c|c|c|c|c|c|c|c|c|}
\hline \multirow[t]{2}{*}{ Characteristics } & \multicolumn{4}{|c|}{ CYP3A4 rs3735451 } & \multicolumn{4}{|c|}{ CYP3A4 rs4646440 } \\
\hline & $\pi$ & $\mathrm{TC}$ & $\mathrm{CC}$ & $p$ & AA & $A G$ & GG & $p$ \\
\hline TP $(g / L)$ & $66.16 \pm 6.02$ & $64.65 \pm 5.34$ & $66.79 \pm 6.09$ & 0.021 & $66.98 \pm 6.96$ & $64.60 \pm 5.33$ & $66.02 \pm 5.92$ & 0.043 \\
\hline Serum uric acid ( $\mu \mathrm{mol} / \mathrm{L})$ & $290.64 \pm 97.14$ & $279.93 \pm 93.17$ & $260.83 \pm 72.42$ & 0.247 & $266.33 \pm 61.31$ & $280.39 \pm 94.51$ & $287.64 \pm 95.95$ & 0.583 \\
\hline Blood glucose (mmol/L) & $6.36 \pm 2.05$ & $6.22 \pm 2.33$ & $6.77 \pm 3.19$ & 0.484 & $6.75 \pm 2.92$ & $6.35 \pm 2.59$ & $6.29 \pm 2.02$ & 0.734 \\
\hline $\mathrm{TB}(\mu \mathrm{mol} / \mathrm{L})$ & $13.78 \pm 6.99$ & $13.23 \pm 5.32$ & $14.95 \pm 9.03$ & 0.422 & $16.56 \pm 11.62$ & $13.36 \pm 5.23$ & $13.62 \pm 6.75$ & 0.237 \\
\hline $\mathrm{TG}(\mathrm{mmol} / \mathrm{L})$ & $1.55 \pm 0.88$ & $1.65 \pm 1.24$ & $1.53 \pm 1.22$ & 0.596 & $1.79 \pm 1.43$ & $1.60 \pm 1.02$ & $1.57 \pm 1.06$ & 0.771 \\
\hline Hemoglobin (g/L) & $137.07 \pm 21.57$ & $137.51 \pm 22.94$ & $130.46 \pm 31.22$ & 0.395 & $133.57 \pm 15.59$ & $137.31 \pm 25.98$ & $136.82 \pm 21.38$ & 0.842 \\
\hline $\mathrm{TC}(\mathrm{mmol} / \mathrm{L})$ & $3.93 \pm 0.99$ & $3.89 \pm 1.05$ & $3.65 \pm 1.19$ & 0.464 & $3.92 \pm 1.13$ & $3.76 \pm 1.10$ & $3.96 \pm 0.98$ & 0.200 \\
\hline $\mathrm{HDL}-\mathrm{C}(\mathrm{mmol} / \mathrm{L})$ & $1.10 \pm 0.24$ & $1.09 \pm 0.26$ & $1.03 \pm 0.37$ & 0.494 & $1.01 \pm 0.31$ & $1.07 \pm 0.27$ & $1.11 \pm 0.25$ & 0.203 \\
\hline $\mathrm{LDL}-\mathrm{C}(\mathrm{mmol} / \mathrm{L})$ & $1.82 \pm 0.56$ & $1.82 \pm 0.62$ & $1.66 \pm 0.56$ & 0.446 & $1.80 \pm 0.55$ & $1.76 \pm 0.65$ & $1.84 \pm 0.55$ & 0.375 \\
\hline \multirow[t]{2}{*}{ Characteristics } & \multicolumn{4}{|c|}{ CYP11A1 rs12912592 } & \multicolumn{4}{|c|}{ CYP11A1 rs28681535 } \\
\hline & $\pi$ & GT & GG & $p$ & $\pi$ & GT & GG & $p$ \\
\hline TP $(g / L)$ & $65.50 \pm 0.56$ & $65.32 \pm 6.02$ & $65.64 \pm 5.78$ & 0.910 & $65.72 \pm 5.75$ & $65.62 \pm 5.82$ & $65.46 \pm 5.83$ & 0.946 \\
\hline Serum uric acid ( $\mu \mathrm{mol} / \mathrm{L})$ & $245.50 \pm 62.93$ & $290.63 \pm 99.32$ & $284.76 \pm 92.30$ & 0.744 & $2810 \pm 87.44$ & $284.04 \pm 93.26$ & $290.48 \pm 96.95$ & 0.749 \\
\hline Blood glucose (mmol/L) & $4.93 \pm 0.21$ & $6.57 \pm 2.34$ & $6.27 \pm 2.23$ & 0.397 & $6.85 \pm 2.92$ & $6.26 \pm 2.12$ & $6.11 \pm 1.96$ & 0.064 \\
\hline $\mathrm{TB}(\mu \mathrm{mol} / \mathrm{L})$ & $9.33 \pm 2.82$ & $12.02 \pm 4.58$ & $14.05 \pm 6.84$ & 0.025 & $13.71 \pm 6.91$ & $14.23 \pm 7.35$ & $12.75 \pm 4.68$ & 0.117 \\
\hline $\mathrm{TG}(\mathrm{mmol} / \mathrm{L})$ & $0.76 \pm 0.39$ & $1.65 \pm 1.28$ & $1.57 \pm 0.99$ & 0.342 & $1.33 \pm 0.53$ & $1.63 \pm 1.05$ & $1.63 \pm 1.22$ & 0.093 \\
\hline Hemoglobin (g/L) & $130.67 \pm 4.04$ & $136.46 \pm 27.08$ & $136.94 \pm 21.84$ & 0.885 & $137.54+15.96$ & $136.85 \pm 24.84$ & $136.31 \pm 22.92$ & 0.932 \\
\hline $\mathrm{TC}(\mathrm{mmol} / \mathrm{L})$ & $3.64 \pm 0.33$ & $3.97 \pm 1.00$ & $3.89 \pm 1.02$ & 0.774 & $3.96 \pm 0.84$ & $3.95 \pm 1.10$ & $3.81 \pm 0.97$ & 0.433 \\
\hline $\mathrm{HDL}-\mathrm{C}(\mathrm{mmol} / \mathrm{L})$ & $1.21 \pm 0.35$ & $1.07 \pm 0.24$ & $1.09 \pm 0.26$ & 0.579 & $1.16 \pm 0.27$ & $1.08 \pm 0.25$ & $1.06 \pm 0.24$ & 0.027 \\
\hline $\mathrm{LDL}-\mathrm{C}(\mathrm{mmol} / \mathrm{L})$ & $1.86 \pm 0.20$ & $1.84 \pm 0.56$ & $1.81 \pm 0.59$ & 0.871 & $1.88 \pm 0.52$ & $1.83 \pm 0.62$ & $1.75 \pm 0.56$ & 0.311 \\
\hline
\end{tabular}

SNP single nucleotide polymorphism, TP total protein, TB total bilirubin, TC total cholesterol, TG triglyceride, HDL-C high-density lipoprotein cholesterol, $L D L-C$ lowdensity lipoprotein cholesterol

$p<0.05$ indicates statistical significance

Bold indicates that the values have statistical significance

Stroke is a sex-specific disease and the prevalence of stroke in women is lower than that in men [28, 29]. Stratified by gender, we noticed that CYP3A4 rs4646440 and CYP11A1 rs12912592 polymorphism affected IS risk in males but not in females, which indicate that this risk association presented sex difference and emphasize the importance of considering heterogeneity in genetic and stroke association studies. In addition, stroke is a late-onset disease and the rate is higher in older people [30, 31]. Our study found that CYP3A4 rs3735451 and rs4646440 possibly contributed to the susceptibility to IS at age $>61$ years, and CYP3A4 rs4646437 and CYP11A1 rs12912592 and rs28681535 were associated with the risk of IS at age $\leq 61$ years. These suggested the interactions between CYP3A4 and CYP11A1 polymorphisms and some environmental exposures (such as males, elder) contributed to the risk of IS.

Inevitably, our current study has some limitations to be considered. First, due to all participants were all enrolled in the same hospital, the inherent selecting bias and information bias could not be completely excluded for the group of patients with IS. Second, data deficiencies of some exposure factors such as obesity, smoking, and alcohol limited our ability to evaluate gene-environment interaction. Finally, explicit mechanisms of CYP3A4 and CYP11A1 polymorphism on development of IS are still bewildered and further research is needed. Despite the limitations mentioned above, the results of our present study provided scientific evidence of CYP3A4 and CYP11A1 gene with IS for the future studies.

\section{Conclusions}

To sum up, our study provided evidence that variants of CYP3A4 and CYP11A1 gene had a significant effect on the risk of IS in the Chinese Han population, which has not previously been reported. Our study may provide clues for the evaluation of individual susceptibility to IS and increase the understanding of the possible effect of CYP3A4 and CYP11A1 gene on the development of IS. However, the replication of this research in different populations and additional functional analysis is required to completely elucidate the roles by which CYP3A4 and CYP11A1 polymorphisms predispose for IS. 


\section{Supplementary information}

Supplementary information accompanies this paper at https://doi.org/10. 1186/s12883-020-1628-4

Additional file 1: Table S1. Primers sequence of PCR and UEP used in this study. Table S2. Relationships between CYP3A4 polymorphism and Ischemic stroke risk.

\section{Abbreviations}

AA: Arachidonic acid; Cl: Confidence intervals; CYPs: Cytochrome P450s; EETs: Epoxyeicosatrienoic acids; HDL-C: High-density lipoprotein cholesterol; HWE: Hardy-weinberg equilibrium; IS: Ischemic stroke; LD: Linkage disequilibrium; LDL-C: Low-density lipoprotein cholesterol; MAFs: Minor allele frequencies; OR: Odds ratio; SNP: Single-nucleotide polymorphisms; TC: Total cholesterol

\section{Acknowledgements}

We are grateful to the individuals who participated in this study. We also thank the clinicians and hospital staff from the Affliated Hospital of Yan'an University who contributed to the sample and data collection for this study.

\section{Authors' contributions}

The work presented here was carried out in collaboration between all authors. NG carried out the molecular genetic studies and drafted the manuscript. HT and LG designed the methods and experiments, performed the statistical analyses and interpreted the results. GT designed primers and performed the SNP genotyping experiments. HL collected clinical information about patients and performed the SNP genotyping experiments. YX conceived of the study, worked on associated data collection and their interpretation, participated in the design and coordination of the study, and funded the study. All authors read and approved the final manuscript.

\section{Funding}

This work is supported by National Natural Science Foundation of China (No.81760234).

\section{Availability of data and materials}

The datasets used and/or analysed during the current study are available from the corresponding author on reasonable request.

\section{Ethics approval and consent to participate}

All participants were voluntary and provided written informed consent before taking part in this research. This study was approved by the Research Ethics Committee of Haikou People's Hospital, and in compliance with the Declaration of Helsinki. The design and performance of this study involving human subjects were obviously described in a research protocol.

\section{Consent for publication}

Not applicable.

\section{Competing interests}

The authors declare that they have no competing interest.

Received: 11 March 2019 Accepted: 23 January 2020

Published online: 04 March 2020

\section{References}

1. Liu L, Wang D, Wong KS, Wang Y. Stroke and stroke care in China: huge burden, significant workload, and a national priority. Stroke. 2011; 42(12):3651-4

2. Wang $W$, Jiang $B$, Sun $H$, Ru X, Sun $D$, Wang $L$, Wang $L$, Jiang $Y$, Li $Y$, Wang Y, Chen Z, Wu S, Zhang Y, Wang D, Wang Y, Feigin VL. Prevalence, incidence, and mortality of stroke in China: results from a Nationwide population-based survey of 480687 adults. Circulation. 2017;135(8):759-71.

3. Loo KW, Gan SH. Burden of stroke in Malaysia. Int J Stroke. 2012;7(2):165-7.

4. Bejot Y, Daubail B, Giroud M. Epidemiology of stroke and transient ischemic attacks: current knowledge and perspectives. Rev Neurol. 2016;172(1):59-68.

5. Bevan S, Markus HS. Genetic profiles in ischaemic stroke. Curr Atheroscler Rep. 2013;15(8):342.
6. Xue Y, Shi N, Zhang B, Gao X, Gao Y, Zhou X, Du J, Chen P, Ouyang Y, Wang F. Genetic variant in ZFHX3 Geneon 16q22 associated with risk of stroke in Chinese Han population. Int J Clin Exp Pathol. 2016;9:8650-6.

7. Yu J, Luo D, Zhou F, Jin T, Liang X, Yu D. Polymorphism of TNIP1 was associated with atherosclerotic ischemic stroke in southern Han Chinese but unrelated with telomere. Int J Clin Exp Pathol. 2017:10(3):3510-6.

8. He J, Sun S, Zhang M, Ouyang Y, Zhang N, Yang M, Jin T, Xia Y. Association analysis of ALOX5 gene polymorphisms with stroke risk: a case-control study in a Chinese Han population. Int J Clin Exp Pathol. 2016;9(4):4432-7.

9. Larsen BT, Gutterman DD, Hatoum OA. Emerging role of epoxyeicosatrienoic acids in coronary vascular function. Eur J Clin Investig 2006;36(5):293-300.

10. Ward NC, Croft KD, Blacker D, Hankey GJ, Barden A, Mori TA, Puddey IB, Beer CD. Cytochrome P450 metabolites of arachidonic acid are elevated in stroke patients compared with healthy controls. Clin Sci. 2011;121(11):501-7.

11. Yi X, Liao D, Wu L, Chen H, Li J, Wang C. CYP genetic variants, CYP metabolite levels, and symptomatic carotid stenosis in ischemic stroke patients. J Atheroscler Thromb. 2016;23(5):621-31.

12. Yang X, Zhang B, Molony C, Chudin E, Hao K, Zhu J, Gaedigk A, Suver C, Zhong $H$, Leeder JS, Guengerich FP, Strom SC, Schuetz E, Rushmore TH, Ulrich RG, Slatter JG, Schadt EE, Kasarskis A, Lum PY. Systematic genetic and genomic analysis of cytochrome P450 enzyme activities in human liver. Genome Res. 2010;20(8):1020-36.

13. Slominski AT, Li W, Kim TK, Semak I, Wang J, Zjawiony JK, Tuckey RC. Novel activities of CYP11A1 and their potential physiological significance. J Steroid Biochem Mol Biol. 2015;151:25-37.

14. Vanga SR, Good M, Howard PA, Vacek JL. Role of vitamin D in cardiovascular health. Am J Cardiol. 2010;106(6):798-805.

15. Oeth P, del Mistro G, Marnellos G, Shi T, van den Boom D. Qualitative and quantitative genotyping using single base primer extension coupled with matrix-assisted laser desorption/ionization time-of-flight mass spectrometry (MassARRAY). Methods Molec Biol. 2009:578:307-43.

16. Ellis JA, Ong B. The MassARRAY((R)) system for targeted SNP genotyping. Methods Molec Biol. 2017;1492:77-94.

17. Huang H, Al-Shabrawey M, Wang MH. Cyclooxygenase- and cytochrome P450-derived eicosanoids in stroke. Prostaglandins Other Lipid Mediat. 2016;122:45-53.

18. Kim SK, Yim SV, Lee BC. Association between cytochrome P450 promoter polymorphisms and ischemic stroke. Exp Ther Med. 2012;3(2):261-8.

19. Honda A, Miyazaki T, Ikegami T, Iwamoto J, Maeda T, Hirayama T, Saito Y, Teramoto T, Matsuzaki Y. Cholesterol 25-hydroxylation activity of CYP3A. J Lipid Res. 2011;52(8):1509-16.

20. Ayajiki K, Fujioka H, Toda N, Okada S, Minamiyama Y, Imaoka S, Funae Y, Watanabe S, Nakamura A, Okamura T. Mediation of arachidonic acid metabolite(s) produced by endothelial cytochrome P-450 3A4 in monkey arterial relaxation. Hypertens Res. 2003;26(3):237-43.

21. Katsumata N. Genetic defects in pregnenolone synthesis. Pediatr Endocrinol Rev. 2012;10(Suppl 1):98-109.

22. Wang IK, Liu CH, Yen TH, Jeng JS, Hsu SP, Chen CH, Lien LM, Lin RT, Chen AC, Lin HJ, Chi HY, Lai TC, Sun Y, Lee SP, Sung SF, Chen PL, Lee JT, Chiang TR, Lin SK, Muo CH, Ma H, Wen CP, Sung FC, Hsu CY. Cholesterol levels are associated with 30-day mortality from ischemic stroke in dialysis patients. Stroke Cerebrovasc Dis. 2017:26(6):1349-56.

23. Chen CH, Wang SC, Tsou HH, Ho IK, Tian JN, Yu CJ, Hsiao CF, Chou SY, Lin YF, Fang KC, Huang CL, Su LW, Fang YC, Liu ML, Lin KM, Hsu YT, Liu SC, Chen A, Liu YL. Genetic polymorphisms in CYP3A4 are associated with withdrawal symptoms and adverse reactions in methadone maintenance patients. Pharmacogenomics. 2011;12(10):1397-406.

24. Schirmer M, Rosenberger A, Klein K, Kulle B, Toliat MR, Nurnberg P, Zanger UM, Wojnowski L. Sex-dependent genetic markers of CYP3A4 expression and activity in human liver microsomes. Pharmacogenomics. 2007:8(5):443-53.

25. Seo S, Takayama K, Uno K, Ohi K, Hashimoto R, Nishizawa D, Ikeda K, Ozaki $\mathrm{N}$, Nabeshima T, Miyamoto Y. Functional analysis of deep intronic SNP rs13438494 in intron 24 of PCLO gene. PLoS One. 2013;8(10):e76960.

26. Wang D, Sadee W. CYP3A4 intronic SNP rs35599367 (CYP3A4*22) alters RNA splicing. Pharmacogenet Genomics. 2016;26(1):40-3.

27. Zhao H, Yang W, Qiu R, Li J, Xin Q, Wang X, Feng Y, Shan S, Liu Y, Gong Y. An intronic variant associated with systemic lupus erythematosus changes the binding affinity of Yinyang1 to downregulate WDFY4. Genes Immun. 2012;13(7):536. 
28. Poorthuis MH, Algra AM, Algra A, Kappelle LJ, Klijn CJ. Female- and malespecific risk factors for stroke: a systematic review and meta-analysis. JAMA Neurol. 2017;74(1):75-81.

29. Wang J, Ning X, Yang L, Tu J, Gu H, Zhan C, Zhang W, Su TC. Sex differences in trends of incidence and mortality of first-ever stroke in rural Tianjin, China, from 1992 to 2012. Stroke. 2014;45(6):1626-31.

30. Goldstein LB, Bushnell CD, Adams RJ, Appel L, Braun LT, Chaturvedi S, Creager MA, Culebras A, Eckel RH, Hart RG, Hinchey JA, Howard VJ, Jauch EC, Levine SR, Meschia JF, Moore WS, Nixon JV, Pearson TA. Guidelines for the primary prevention of stroke: a guideline for healthcare professionals from the American Heart Association/American Stroke Association. Stroke. 2011;42(2):517-84.

31. O'Donnell MJ, Xavier D, Liu L, Zhang H, Chin SL, Rao-Melacini P, Rangarajan S, Islam S, Pais P, McQueen MJ, Mondo C, Damasceno A, Lopez-Jaramillo P, Hankey GJ, Dans AL, Yusoff K, Truelsen T, Diener HC, Sacco RL, Ryglewicz D, Czlonkowska A, Weimar C, Wang X, Yusuf S. Risk factors for ischaemic and intracerebral haemorrhagic stroke in 22 countries (the INTERSTROKE study): a case-control study. Lancet. 2010;376(9735):112-23.

\section{Publisher's Note}

Springer Nature remains neutral with regard to jurisdictional claims in published maps and institutional affiliations.

Ready to submit your research? Choose BMC and benefit from:

- fast, convenient online submission

- thorough peer review by experienced researchers in your field

- rapid publication on acceptance

- support for research data, including large and complex data types

- gold Open Access which fosters wider collaboration and increased citations

- maximum visibility for your research: over $100 \mathrm{M}$ website views per year

At BMC, research is always in progress.

Learn more biomedcentral.com/submissions 